\title{
ADMINISTRAÇÃO PÚBLICA E VEDAÇÃO AO NEPOTISMO NO PODER JUDICIÁRIO
}

PUBLIC ADMINISTRATION AND THE PROHIBITION OF NEPOTISM IN JUDICIARY POWER

Alexandre de Moraes

Resumo:

A Administração Pública deve ser impessoal; o agente público deve visar o interesse público e não a satisfação de seus interesses pessoais ou familiar. Essa assertiva e outras são abordadas neste trabalho pelo autor.

Palavras-chave: Administração Pública. Nepotismo. Conselho Nacional de Justiça. Ato jurídico . Ética institucional.

Abstract:

Public Administration shall be impersonal; public agent shall aim the public interest, not his personal or familiar interests. This assertion and other ones are treated by the author in this work.

Keywords: Public Administration. Nepotism. National Justice Council. Juridical Acts. Instititional Ethics.

1. Princípios da Administração Pública e Nepotismo

O nepotismo no Poder Judiciário e sua interpretação perante os princípios da legalidade, impessoalidade, igualdade e moralidade administrativa devem ser analisados sob três aspectos:

1) Se a vedação ao nepotismo é preceito implícito derivado diretamente da Constituição Federal e dos princípios regentes da Administração Pública ou se o texto constitucional ignora o assunto e, conseqüentemente, permite ao legislador ordinário sua livre regulação;

2) Eventual existência de direito adquirido ou ato juridico perfeito a cargos em comissão ou funções de confiança;

3) Competência constitucional do Conselho Nacional de Justiça para coibir a prática do nepotismo no Poder Judiciário Nacional.

Membro do Conselho Nacional de Justiça. Doutor e Livre-docente em Direito Constituciunal pela Faculdade de Direito da Universidade de São Paulo. Professor Associado da Faculdade de Dircito da Universidade de São Paulo e Professor Titular da Ĺniversidade Mackenzie. Ex-secretárin de Estado da Justiça c da Defesa da Cidadania (2002-2005). 
A primeira questão - a mais importante, pois condiciona as demais é a necessidade de se definir se a vedação ao nepotismo é preceito implícito da Administração Pública, derivado dirctamente da Constituição Federal, em especial dos principios da moralidade e da impessoalidade, ou se o texto constitucional simplesmente ignora a matéria, deixando ao legislador ordinário sua regulamentação, como bem entender, seja proibindo, seja autorizando.

Se optarmos pela segunda hipótese - matéria infraconstitucional . não haverá possibilidade de controle administrativo nem pelo Conselho Nacional de Justiça, nem pelos próprios tribunais, pois suas competências administrativas limitar-se-ão à análise dos casos específicos que desrespeitarem a legislação, que deverá ser observada integralmente, mesmo que consagre a prática do nepotismo. O máximo que a competência constitucional permitiria ao CNJ - repita-se, caso o entendimento scja de tratar-se de matéria infraconstitucional - seria a fiscalização da observância do efetivo cumprimento da legislação.

Não me parece, com o devido respeito às importantes posições em contrário, que seja a correta interpretação constitucional.

A Constituição da República consagra os princípios da impessoalidade e da moralidade no cuput do art. 37, e determina expressamente competir ao Conselho Nacional de Justiça a fiscalização e sua efetivação no âmbito do Poder Judiciário (CF, art. 103-B, $\left.\$ 4^{\circ} \mathrm{II}\right)$.

A Administração Pública deve ser impessoal, ou seja, o agente público deve visar o interesse público e não a satisfação de seus interesses pessoais ou familiares.

Nas nomeações de cargos $\mathrm{cm}$ comissão ou funções de confiança, os órgãos diretivos do Poder Judiciário atuam como executor do ato, que serve de veículo de manifestação da vontade estatal e, portanto, as realizações administrativogovernamentais não são simplesmente do agente político, mas sim da entidade pública em nome da qual atuou, na hipótese, o Poder Judiciário, que deve agir de forma impessoal e moral.

Pelo princípio da moralidade administrativa, não bastará ao administrador o cumprimento da estrita legalidade, devendo ele, no exercicio de sua função pública. respeitar os princípios morais e éticos de razoabilidade e justiça, pois a moralidade constitui, a partir da Constituição de 1988, pressuposto de validade de todo ato da administração pública. Como ressaltado por Hely Lopes Meirelles, "não se trata diz Hauriou, o sistematizador de tal conceito, da moral comum, mas sim de uma moral 
jurídica, entendida como o conjunto de regras de cunduta tiradas da disciplina interior da Administração" '

A moral juridica deverá. cumo ensina Maria Sylvia Zanella Di Pietro. observar o senso comum de honestidade, retidão. equilíbrio, justiça '’ ética das instituições."

Dessa forma, o Conselho Nacional de Justiça, ao exercer sua função constitucional, não deve se restringir ao exame restrito da legalidade do ato administrativo. mas sim, entender por legalidade ou legilimidade não-só a conformação do ato com a lei, como também com a moral administrativa e com o interesse coletivo. pois como lembrado pelo Supremo Tribunal Federal, "poder-se-á dizer que apenas agora a Constituição Federal consagrou a moralidade como princípio de administração pública (art. 37 da Constituição Federal). Isso não é verdade. Os princípios podem estar ou-não explicitados em normas. Normalmente. sequer constam de texto regrado. Deflue no todo do ordenamento jurídico. Encontram-se insitos, implícitos no sistema, permeando as diversas normas regedoras de determinada matéria. $\mathrm{O}$ só fato de um princípio não figurar no texto constitucional, não significa que nunca teve relevância de princípio. A circunstância de, no texto constitucional anterior, não figurar o princípio da moralidade não significa que o administrador poderia agir de forma imoral ou mesmo amoral... Os princípios gerais de Direito existem por força própria, independentemente de figurarem em texto legislativo. E o fato de passarem a figurar em texto constitucional ou legal não lhes retira o caráter de princípio" 3

Como afirmado pelo min. Marco Aurélio, "o agente público não só tem que ser honesto e probo, mas tem que mostrar que possui tal qualidade. Como a mulher de César"

O princípio da moralidade cstá intimamente ligado à idéia de prohidade. dever inerente do administrador público, e somente sua integral observância no preenchimento dos cargos em comissão e funções de confiança no Poder Judiciário respeitará o texto constitucional.

A interpretação das normas constitucionais e sua supremacia devem ser estabelecidas mediante a realidade atual da sociedade, pois como lembrado por Konrad Ilesse, "a Constituição jurídica está condicionada pela realidade histórica. Fla não pode ser separada da realidade concreta de seu tempo. A pretensão de eficácia da Constituição somente pode ser realizada se se levar em conta essa realidade. (...) A Constituição

MEIRELleS, Hely Lopes. Direito Administrativo brasileiro, 21 ed. São Paulo: Malhciros, 1995. p. 82.

DI PIETRO, Maria Sylvia Zanella. Discricionariedade administrativa na Constituição de 1988. São Paulo: Atlas, 1999. p. 111.

3 STF. 2 ${ }^{\text {a }}$ T. Rel. Min. Marco Aurélio. Rextr. n. 160.381/SP. RTJ 153/1.030. 
jurídica logra conferir forma e modificação à realidade. Ela logra despertar a força que reside na natureza das coisas, tornando-a ativa. Ela própria converte-se em força ativa que influi e determina a realidade política e social. Essa força impõe-se de forma tanto mais efetiva quanto mais ampla for a conviç̧ão sobre a inviolabilidade da Constituição" 4

Portanto, me parece claro que a vedação ao nepotismo tem substrato constitucional como verificamos no STF, na ADIN/RS, medida cautelar n. 1.52l, Rel. Min. Marco Aurélio, DJ, 17-3-2000 e no TCU, 2 ${ }^{\mathrm{a}}$ T, rel. min. Adylson Motta, Acórdão n. 393, de 18-3-2004 e, conseqüentemente, sua vedação teve início na data de 5 de outubro de 1988, independentemente de qualquer legislação posterior.

2. Nepotismo e inexistência de Direito Adquirido ou ato jurídico perfeito

A segunda importante questão a ser analisada na presente hipótese diz respeito à inexistência de direito adquirido ou ato juridico perfeito a cargos em comissão, cujas nomeações e investiduras precárias desrespeitaram flagrantemente as normas constitucionais.

O entendimento contrário e baseado na possibilidade de mantença da validade dos cargos em comissão nomeados antes da edição de legislação infraconstitucional, pela existência de direito adquirido - com o devido respeito convalidaria nomeações inconstitucionais, criando nova forma de estabilidade a servidores públicos não-concursados e não prevista no art. 41 do texto constitucional, que exige como requisito para aquisição de estabilidade do servidor público a nomeação para cargo de provimento efetivo em virtude de concurso público, conforme decidiu o Supremo Tribunal Federal ao afirmar não ser lícito qualquer previsão de estabilidade fora das hipóteses constitucionais, sendo nulo e de nenhum cfeito qualquer disposição nesse sentido. 5

Como justificar que o nepotismo fere a Constituição Federal, porém que aqueles que foram nomeados antes da edição de leis regulamentadoras - que, repita-se, são desnecessárias, pois a vedação ao nepotismo é inconstitucional - possam se favorecer de atos inconstitucionais por ferimento à IMPESSOALIDADE e MORALIDADE constitucionais?

Além disso, como afirmar - com a devida vênia aos posicionamentos em contrário, que a nomeação de parentes, com claro ferimento aos princípios constitucionais da impessoalidade e moralidade, não seja viciada, sendo o respectivo ato

HESSE, Konrad. A força normativa da constituição. Porto Alegre: Sergio Fabris, 1991. p. 24.

RTJ, $164 / 293$ e $165 / 684$. 
administrativo imoral e inconstitucional, impossivel de convalidação, por também inexistente $o$ ato jurídico perfeito?

Ato jurídico perfeito é aquele que reúne todos os seus elementos constitutivos exigidos pela lei, sendo em virtude da necessidade de proteção ao princípio da segurança jurídica, protegido pela Constituição, ${ }^{6}$ pois como ressaltado pelo ministro Moreira Alves, "o art. $5^{\circ}$ XXXVI consagra princípio fundamental destinada a resguardar a incolumidade das situações jurídicas definitivamente consolidadas" 7

Impossivel afirmar que uma nomeação para cargo em comissão com a prática de nepotismo e com flagrante ferimento aos princípios da impessoalidade e moralidade seja definitivamente consolidada, pois o que deve prevalecer é o texto constitucional, desrespeitado pela investidura dos parentes ou afins próximos aos membros do Poder Judiciário.

Nesse sentido, podemos citar decisão do Tribunal de Contas da União, de lavra do ministro-relator Adylson Motta, que afirmou que essas nomeações ferem "o principio da moralidade na Administração. contemplado no art. 37 da Constituição Federal" para concluir que "ainda que as nomeações houvessem ocorrido antes da Constituição de 1988 - quando foi incorporado ao nosso ordenamento, de forma expressa e definitiva, o princípio da moralidade na Administração Pública -, a manutenção, em si, de um parente em cargo comissionado, por um magistrado, em seu próprio gabinete, configura fato imoral e ilegal, a ser ilidido. Em outras palavras, perde importância perquirir se o servidor foi nomeado antes da publicação do entendimento normativo deste Tribunal ou da promulgação da Constituição de 1988. Importa, sim, reconhecer que, com a proibição do nepotismo na Justiça do Trabalho, tornou-se irregular a manutenção de comissionados sob tal condição"s

3. Atuação do Conselho Nacional de Justiça no combate ao nepotismo

Finalmente, a terceira e última importante questão a ser analisada na presente hipótese, diz respeito à possibilidade da atuação do Conselho Nacional de Justiça, no sentido de possuir competência para coibir a prática do nepotismo no Poder Judiciário Nacional.

Conforme afirmado anteriormente, a Constituição da República consagra os principios da impessoalidade e da moralidade no caput do art. 37, e determina expressamente competir ao Conselho Nacional de Justiça a fiscalização e sua efetivação

8 TCU $2^{3}$ Càmara - Acórdão 293/2004. 
no âmbito do Poder Judiciário (CF, art. 103-B, $\S 4^{\circ}$, II), com a possibilidade de analisar a legalidade de atos administrativos e desconstituí-los, bem como fixar prazo para que se adotem providências necessárias ao exato cumprimento da Constituição e da legislação.

Não me parece, em consonância com a previsão constitucional, a afirmação da impossibilidade do CNJ revogar ato administrativo por inexistência de lei que vede a nomeação de parentes no Poder Judiciário.

A prática do nepotismo, conforme exposto anteriormente, decorre do próprio texto constitucional, bem como, decorre da Constituição Federal a possibilidade do Conselho Nacional de Justiça desconstituir atos administrativos editados contrariamente ao ordenamento jurídico.

As contratações de parentes pelos Tribunais, com fundamento em sua autonomia administrativa ( $(\mathrm{F}$, arts. 96 e 99 ), apesar de poder ser considerada um ato administrativo discricionário, permite ao CNJ a análise de sua legalidade e moralidade, mesmo porque, sempre é bom lembrar, a discricionariedade na edição de atos administrativos mesmo nos Tribunais -, deve ser entendida como o juizo de conveniência e oportunidade do administrador para. entre as hipóteses legais e moralmente admissiveis, escolher aquela que entender como a melhor para o interesse público.

$\mathrm{O}$ ato administrativo discricionário jamais poderá desviar-se de sua finalidade de persecução do interesse público, sob pena de ilegalidade (teoria relativa ao desvio de poder ou de finalidade) e necessidade de desconstituição administrativa ou judiciária.

Caso o Conselho Nacional de Justiça entendesse constitucional a prática de nepotismo no Poder Judiciário, por inexistir texto legal expresso, estaria chancelando uma das práticas mais imorais, antiéticas, não-razoáveis e contrária ao sentimento geral de justiça e legalidade da sociedade.

Além disso, estaria o Conselho Nacional de Justiça afirmando que a questão do nepotismo no Poder Judiciário não é constitucional, mas sim meramente legal, e, conseqüentemente, estará permitindo que futura legislação, inclusive, viesse a consagrar essa prática nefasta, em total descompasso com os princípios da Administração Pública.

$\mathrm{Na}$ presente hipótese, para invalidar os atos administrativos que frontalmente desrespeitam a moralidade administrativa, não é necessário, como ensina Maria Sylvia Zanella Di Pietro, "entrar na dificil análise dos fins que inspiraram a autoridade; o ato em si, o seu objeto, o seu conteuido, contraria a ética da instituição, 
afronta a norma de conduta aceita como legítima pela coletividade administrada. $\mathrm{Na}$ aferição da imoralidade administrativa, é essencial o principio da razoabilidade" 9

Não é razoável entender que o nepotismo no Poder Judiciário respeita os princípios da Administração Pública. Não é razoável entender que o nepotismo no Poder Judiciário não configura desrespeito aos principios da impessoalidade e moralidade. Não é razoável entender que o nepotismo no Poder Judiciário é permitido, simplesmente, por que não existe lei que o proíba.

Dessa forma, a Constituição Federal veda a prática do nepotismo, devendo o Conselho Nacional de Justiça cumprir sua função constitucional de zelar pela fiel observância dos princípios da Administração Pública no Poder Judiciário, e, conseqüentemente, determinar a vedação, salvo se servidor ocupante de cargo de provimento efetivo do Poder Judiciário, de nomeação para cargo em comissão ou designação para função de confiança, de cônjuge, companheiro, parente ou afim, em linha reta ou colateral, até terceiro grau, de qualquer magistrado, em qualquer juízo ou Tribunal do País, inclusive superior.

A necessidade de estabelecimento da amplitude da vedação do nepotismo em qualquer juízo ou Tribunal do País, inclusive superior, visa evitar eventual hipótese conhecida como nepotismo cruzado, ou seja, nomeação de parentes ou afins de magistrado em gabinetes de outros magistrados.

4. Resolução CNJ n. 07/05 e vedação ao nepotismo no âmbito do Poder Judiciário

A Resolução CNJ n. 07, de 18 de outubro de 2005, disciplinou o exercício de cargos, empregos e funções por parentes, cônjuges e companheiros de magistrados e de servidores investidos em cargos de direção e assessoramento, no âmbito dos órgãos do Poder Judiciário e dá outras providências. nos termos do disposto no art. 103-B, $\S 4^{\circ}$ II, da Constituição Federal, e em respeito aos princípios da moralidade e da impessoalidade consagrados no art. 37, caput. da Constituição. Em seu art. $1^{\circ}$ afirmou ser "vedada a prática de nepotismo no âmbito de todos os órgãos do Poder Judiciário. sendo nulos os atos assim caracterizados"

Em seu art. $2^{\circ}$ a Resolução CNJ n. 07/05 prevê que: Constituem práticas de nepotismo, dentre outras: I - o exercício de cargo de provimento em comissão ou de função gratificada, no âmbito da jurisdição de cada Tribunal ou Juízo, por cônjuge. companheiro ou parente em linha reta, colateral ou por afinidade, até o terceiro grau. inclusive, dos respectivos membros ou juízes vinculados; II - o exercício, em Tribunais

9 DI PIETRO, Maria Sylvı Lanella. Discricionariedade administrativa na Constituição de 1988. São Paulo: Atlas. 1999. p. 111. 
ou Juízos diversos, de cargos de provimento em comissão, ou de funções gratificadas, por cônjuges, companheiros ou parentes em linha reta, colateral ou por afinidade, até o terceiro grau, inclusive, de dois ou mais magistrados, ou de servidores investidos em cargos de direção ou de assessoramento, em circunstâncias que caracterizem ajuste para burlar a regra do inciso anterior mediante reciprocidade nas nomeações ou designações; IIl o exercício de cargo de provimento em comissão ou de função gratificada, no âmbito da jurisdição de cada Tribunal ou Juízo, por cônjuge, companheiro ou parente em linha reta, colateral ou por afinidade, até o terceiro grau, inclusive, de qualquer servidor investido em cargo de direção ou de assessoramento; IV a contratação por tempo determinado para atender a necessidade temporária de excepcional interesse público, de cônjuge, companheiro ou parente em linha reta, colateral ou por afinidade, até o terceiro grau, inclusive, dos respectivos membros ou juízes vinculados, bem como de qualquer servidor investido em cargo de direção ou de assessoramento; V a contratação, em casos excepcionais de dispensa ou inexigibilidade de licitação, de pessoa jurídica da qual sejam sócios cônjuge, companheiro ou parente em linha reta ou colateral até o terceiro grau, inclusive, dos respectivos membros ou juizes vinculados, ou servidor investido em cargo de direção e de assessoramento.

$\mathrm{O} C \mathrm{CN}$ excepcionou as seguintes situações, no $\S^{\circ}$ art. $2^{\circ}$, da Res. 07/05: "Ficam excepcionadas, nas hipóteses dos incisos I, II e III deste artigo, as nomeações ou designações de servidores ocupantes de cargo de provimento efetivo das carreiras judiciárias, admitidos por concurso público, observada a compatibilidade do grau de escolaridade do cargo de origem, a qualificação profissional do servidor e a complexidade inerente ao cargo em comissão a ser exercido, vedada, em qualquer caso a nomeação ou designação para servir subordinado ao magistrado ou servidor determinante da incompatibilidade. $\S 2^{\circ} \mathrm{A}$ vedação constante do inciso IV deste artigo não se aplica quando a contratação por tempo determinado para atender a necessidade temporária de excepcional interesse público houver sido precedida de regular processo seletivo, em cumprimento de preceito legal.

$\mathrm{O}$ art. $3^{\circ}$ da Resolução $\mathrm{CNJ}$ n. 07/05, com sua redação dada pela Resolução n. 09/05, determina que "'é vedada a manutenção, aditamento ou prorrogação de contrato de prestação de serviços com empresa que venha a contratar empregados que sejam cônjuges, companheiros ou parentes em linha reta, colateral ou por afinidade, até o terceiro grau, inclusive, de ocupantes de cargos de direção e de assessoramento, de membros ou juizes vinculados ao respectivo Tribunal contratante, devendo tal condição constar expressamente dos editais de licitação" 
5. Supremo Tribunal Federal e Constitucionalidade da Resolução CNJ n. 07/05

O Supremo Tribunal Federal, por maioria $(9 \times 1)$, concedeu liminar para suspender, com efeito vinculante e retroativo, até o exame de mérito, o julgamento de todas as ações no País que questionam a resolução do $\mathrm{CNJ}$, bem como as decisões já proferidas contra a norma do Conselho. ${ }^{10}$

O Supremo Tribunal Federal entendeu, em sede cautelar, que o nepotismo fere os princípios da impessoalidade, moralidade, igualdade e eficiência.

Como bem destacado pelo ministro-relator Carlos Britto, o nepotismo fere os princípios da impessoalidade, eficiência e igualdade, podendo "resvalar na imoralidade administrativa" Em relação ao principio da impessoalidade, destacou que "na absoluta separação entre o público e o privado, ou entre a Administração e o administrador, segundo a republicana metáfora de que "não se pode fazer corlesia com o chapéu alheio" Conceitos que se contrapõem à multisecular cultura do patrimonialismo e que se vulnerabilizam, não há negar, com a prática do chamado "nepotismo" Traduzido este no mais renitente vezo da nomeação ou da designação de parentes não-concursados para trabalhar, comissionadamente ou em função de confiança, debaixo da aba familiar dos seus próprios nomeantes. Seja ostensivamente, seja pela fórmula enrustida do "cruzamento" (situação em que uma autoridade recruta o parente de um colega para ocupar cargo ou função de confiança, em troca do mesmo favor). Em relação ao principio da eficiencia afirmou que os conceitos do recrutamento de mão-deobra qualificada, capacitação técnica e assiduidade "passam a experimentar bem mais dificil possibilidade de transporte para o mundo das realidades empíricas, num ambiente de projeção do doméstico na intimidade das repartições estatais, a começar pela óbvia razão de que já não se tem a necessária isenção, em regra, quando se vai avaliar a capacitação profissional de um parente ou familiar. Quando se vai cobrar assiduidade e pontualidade no comparecimento ao trabalho. Mais ainda, quando se é preciso punir exemplarmente o servidor faltoso (como castigar na devida medida um pai, a própria mãe, um filho, um(a)esposo (a) ou companheiro (a), um(a) sobrinho (a), enfim, com quem eventualmente se trabalhe em posição hierárquica superior?). F: como impedir que os colegas não-parentes ou não-familiares se sintam em posição de menos obsequioso tratamento funcional? Em suma, como desconhecer que a sobrevinda de uma enfermidade mais séria, um trauma psicotísico ou um transe existencial de membros de u a mesma familia tenda a repercutir negativamente na rotina de um trabalho que é comum a todos? O que já significa a paroquial fusão do ambiente caseiro com o espaço

10 Decisào do dia 16-2-06 e ATA do STF publicada no Diário da Justiça. Seção I, 22 fev. 2006. 
público. Para não dizer a confusão mesma entre tomar posse nos cargos e tomar posse dos cargos, na contramão do insuperável conceito de que "administrar não é atividade de quem é senhor de coisa própria, mas gestor de coisa alheia" (Rui Cirne Lima)" Por fim, em relação ao principio da igualdade, concluiu que "o mais facilitado acesso de parentes e familiares aos cargos em comissão e funções de confiança traz consigo os exteriores sinais de uma prevalência do critério doméstico sobre os parâmetros da capacitação profissional; mesmo que não seja sempre assim. Isto sem mencionar o fato de que essa cultura da prevalente arregimentação de mão-de-obra familiar e parental costuma carrear para os núcleos familiares assim favorecidos uma superafetação de renda, poder político e prestigio social" "

6. Conclusão

A prática do nepotismo é injustificável em nossa realidade atual, é imoral, fere a ética institucional que deve reger os Poderes do Estado, pois fere o senso de razoabilidade da comunidade a utilização de cargos públicos para o favorecimento familiar e garantia de empregabilidade doméstica.

A única interpretação possível na presente hipótese, que consagra a supremacia da Constituição e de seus principios e a conseqüente vinculação irrestrita do Poder Judiciário às suas normas, afasta qualquer possibilidade de nepotismo, pois caso contrário não terá respeitado a funçũo promocionul da constituição, mas sim, correremos o perigoso risco, como lembra Canotilho, de eficácia zcro do Direito Constitucional, " e conseqüente desmoralização e perda de credibilidade das Instituições.

São Paulo. dezembro de 2006.

STF - Pleno - ADC 12 - medida cautelar - Rel. Min. Carlos Britto, decisào: 16-2-06.

12 CANOTILLO, J. J. Gomes. Constituição dirigente e vinculaçẫo do legislador: Coimbra: Coimbra Editora. 1994. p. 474. 